\title{
Gianpietro Del Piero: a continuator of the Italian tradition in continuum mechanics, as started by Gabrio Piola
}

Published online: 21 December 2012

(c) Springer-Verlag Berlin Heidelberg 2012

I had the opportunity to meet Gianpietro Del Piero only recently. Indeed, even if I followed several of his inspired lectures and seminars during the years, I did not have the occasion of talking with him on scientific subjects until 2010. This occasion came with a decision of the Scientific Committee of the First Sperlonga Summer School on Mechanics and Engineering Sciences, held in September 2011, whose subject was "Atomistic and continuum descriptions of microstructures".

Indeed, agreeing with the proposal of Antonio Di Carlo, the Committee decided to put Prof. Del Piero and Prof. Presutti in charge for the 2011 edition of the school. In order to organize the school, Prof. Del Piero visited me several times, discussed with me about many scientific and non-scientific subjects, and shared with me his vision about many aspects of life and his experience about academy, science and human beings.

A consequence of these meetings was that I was able to better understand my own papers, thanks to the deep criticisms of their foundations made by Prof. Del Piero. Also, I understood better some of his papers. A few months later, with the support of Samuel Forest, I decided to submit to the Editor-in-chief of Continuum Mechanics and Thermodynamics a proposal for the present special issue, which gathers some of the contributions presented at the Symposium in honor of Gianpietro Del Piero, in occasion of his retirement. This event took place at the end of the School cited above. (http://www.sdelevicivita.it/category/videolezioni/ symposiumdelpiero/) Later, Samuel and myself decided to extend the invitation to publish a paper in this special issue to other scientists working in the same area and sharing the taste for rigorous presentations.

Since our first meeting at the Smart Materials and Structures Laboratory in Cisterna di Latina, I had the pleasure to meet Gianpietro periodically, and to discuss with him a lot: during these meetings, projects for joint papers started to be made.

I am not sure that any paper will be completed rapidly, because, as I have learnt quickly, the most demanding reviewer of Del Piero's papers is Del Piero himself. I have seen him to abandon a nearly completed paper, which many of our colleagues would have considered a good one, simply because he considered it not original enough.

In a time of h-indices, impact factors, and citations counting, this sound attitude toward publishing activity is an example to be followed: it is indeed absolutely useless, except maybe for somebody's career or somebody's else inflated self-esteem, to publish papers with a poor innovative content. In another occasion, I had the opportunity of discussing about these subjects, and many others related to Ancient Science, with Gianpietro and Lucio Russo, the author of the remarkable book "The Forgotten Revolution" published by Springer. Indeed I discovered, with my great intellectual amusement, that Gianpietro had enthusiastically read the book and that he was eager to discuss with the author.

F. dell'Isola $(\varangle)$

Dipartimento di Ingegneria Strutturale e Geotecnica, Sapienza Università di Roma, Via Eudossiana, 18, 00198 Roma, Italy

E-mail: francesco.dellisola@uniroma1.it; fdellisola@gmail.com 
The dinner which the three of us had was a true intellectual enjoyment. We agreed-for instance-that the decline of the technology in domes construction was a confirm of Russo's ideas about the general decline of science and technology. Moreover, we agreed that the risks of a degradation of scientific knowledge are always present and that in our times, they seem to be particularly dangerous.

Gianpietro Del Piero is not writing so many papers, because he is pondering them seriously. However, he does not suffer of the disease of extreme and compulsive perfectionism: he manages to be happy with a good approximation of perfection. Therefore, he manages, by means of carefully written papers, to spread his sometimes very original ideas and scientific conceptions.

In the same way, his lectures are rigorous, precise and demanding, very demanding. The audience is asked to reason step by step with him to follow the arguments which he presents at a breathtaking rhythm. He demands to his audience much less than he demanded to himself while preparing his lectures, but still the majority of the persons suffer the great intellectual effort they require.

In many aspects, he is a continuator of Piola's scientific work: Gianpietro Del Piero was among those who infused in (Continuum) Mechanics some of the mathematical rigor needed for its development. Like Piola, he used advanced mathematical tools to found Continuum Mechanics on solid bases, but, like Piola, he never lost contact with applications. One night, after a glass of wine, he admitted that he had another very important point in common with Piola: they both share their family names with an outstanding football player!

Gianpietro belongs to the age of reason: his vision of life is based on the rational analysis of problems and on the effort of finding rational solutions. He is also a very opinionated person: his beliefs are strong as is his personality. I personally do not agree with many of his opinions: however, we managed to discuss peacefully about our divergent opinions, because, perhaps contrary to common belief, Gianpietro is very tolerant and open minded. In his political, scientific and cultural battles, he always fought in absolute good faith, and he is capable to understand and admit when and where he was wrong.

As happened to many "caposcuola" (i.e. leaders of a scientific group), he played an eminent role in academic politics during his career. Although some of his choices were considered controversial, I am persuaded that also in this role he tried to do his best for the advancement of science and for the well-being of Italian academic institutions. Looking at his scientific results and at his academic choices, I hope that for a long time, after his retirement, he will be given the force to continue his intellectual activity.

For his life, he worked

\section{AD SCIENTIARUM HAUSTUM ET SEMINARIUM DOCTRINARUM}

towards a source of science and a seedbed of doctrine,

as demanded by Frederick the Second Hohenstaufen to the professors of my Alma Mater. 